\title{
O continuum de gramaticalização do verbo DAR: de predicador a auxiliar
}

\author{
Sueli Maria Coelho* \\ Silmara Eliza de Paula Silva**
}

\begin{abstract}
Resumo
Esta pesquisa investigou, numa perspectiva diacrônica, o processo de gramaticalização do verbo DAR na língua portuguesa, com o objetivo de traçar seu continuum de mudança gramatical. Tomando como objeto de análise um corpus constituído de 3.288 ocorrências do verbo selecionado pelo estudo, coletadas no banco de dados do Corpus do Português (DAVIES; FERREIRA, 2006), constatou-se que, ao longo dos séculos, esse verbo mudou de categoria, passando de predicador a auxiliar. Essa multifuncionalidade decorreu de um processo cognitivo de abstração semântica, o que fez com que, no percurso de sua história linguística, o verbo DAR perdesse algumas de suas propriedades gramaticais - entre as quais a capacidade de selecionar argumentos - em detrimento da incorporação de outras - como a expressão da modalidade e a marcação do aspecto verbal - em construções cuja estrutura é a seguinte: $\mathrm{V} 1_{\mathrm{DAR}}+\mathrm{PREP}_{\mathrm{p}(\mathrm{a}) \mathrm{ra}}+\mathrm{V} 2_{\text {infinitivo. }}$ A análise dos dados permitiu chegar ao seguinte continuum de mudança: predicador $>$ verbo leve $>$ mesoconstrução $>$ modal epistêmico $>$ marcador aspectual.
\end{abstract}

Palavras-chave: Gramaticalização. Verbo leve. Perífrases verbais. Modalidade. Aspecto verbal.

\section{Considerações iniciais}

A máxima sociolinguística de que a língua é dinâmica e, portanto, sensível à variação e à mudança é tributária de Labov (1972) e difundida, desde então, por diversos estudiosos de questões variacionistas da língua(gem), quer na perspectiva laboviana, quer em perspectivas metodológicas que buscam estabelecer uma interface entre o quadro teórico da variação e outros, como o da gramaticalização

*Universidade Federal de Minas Gerais (UFMG).

**Universidade Federal de Minas Gerais (UFMG). 
e o da semântica cognitiva, por exemplo. Nessa abordagem de interface, os pesquisadores buscam não apenas analisar o processo de variação e de possível mudança de um item ou construção, como também explicar as motivações linguísticas e cognitivas atuantes no processo da mudança categorial. $\mathrm{Na}$ esteira desses estudos, esta pesquisa buscou investigar e descrever, numa perspectiva diacrônica, o processo de gramaticalização do verbo DAR na língua portuguesa, com o objetivo de traçar seu continuum de mudança. Partimos da hipótese de que a referida forma, ao perder propriedade lexical e se juntar a uma preposição seguida de outras formas verbais flexionadas no infinitivo, forma uma construção verbal e passa a desempenhar, nesse contexto, funções gramaticais relacionadas à expressão da modalidade e do aspecto, conforme ilustram estes exemplos:

(1) "Foi um apartamento que meu avô DEU pra minha mãe morar quando ela casou." (séc. XX) (forma lexical = verbo predicador)

(2) "Não se podia dizer que fosse de mau modo, mas DAVA pra ver que era má vontade (...)" (séc. XX) (forma gramatical = auxiliar marcador de modalidade)

(3) "O sujeito já DEU pra beber, está jogando, e, tolo, bem tolo, vendeu-se à Supi." (séc. XIX) (forma gramatical = auxiliar marcador aspectual)

Em (1), ilustramos uma ocorrência do verbo DAR empregado como predicador, dotado de suas propriedades lexicais de selecionar argumentos e de atribuir papéis semânticos. Já em (2) e em (3), essa forma passou por um processo metafórico de abstração semântica, o que determinou que a ideia de transferência de posse concreta, presente em (1), se esvaísse, além do que não lhe cabe mais, na função de verbo auxiliar, a seleção argumental. Nesses contextos, comporta-se, pois, como uma categoria funcional, introduzindo, respectivamente, modalidade epistêmica e conotação aspectual. Tal conotação de aspecto carrega a idiossincrasia de marcar, conforme já previra Castilho (1968), ao menos dois valores aspectuais paralelos, já que "o sujeito" dá início a uma ação (beber) não praticada no passado (aspecto incoativo) e reincide nela, o que configura a iteração.

Esse processo de mudança via emergência de novas formas gramaticais a partir de formas lexicais evidencia que a gramática da língua não é uma estrutura fechada que se opõe ao léxico, mas que, embora em menor grau e em condições específicas, é também dinâmica e sensível às intervenções de seus sujeitos falantes. De acordo com HOPPER e TRAUGOTT, 
não há um caminho único para emergência de novas formas gramaticais, mas há passos que podem ser identificados. Entre estes, a recorrência de certos usos do item lexical em contextos lingüísticos altamente específicos, a partir dos quais ele se idiomatizaria numa determinada construção gramatical, cuja erosão morfológica pode ser esperada no curso do tempo.

(2003 apud VELLOSO, 2007, p. 100)

Os exemplos arrolados, além de comprovarem a sensibilidade da gramática a novas incorporações, conforme defendido por Hopper e Traugott, demonstram ainda que o processo de mudança categorial de predicador a auxiliar difere daquele proposto pela teoria laboviana, dado que, nesse caso específico, não existem concorrência e substituição de formas. No processo de mudança categorial por gramaticalização, tem-se, ao contrário, uma espécie de reengenharia de formas, já que, por meio de um processo cognitivo de abstração semântica, a forma lexical perde propriedades inerentes a essa categoria, assumindo propriedades de categoria funcional. Esse processo de emergência de "novas" formas e funções a partir de formas já preexistentes na língua não implica o desaparecimento da forma "antiga", pois, segundo prevê o princípio da estratificação, proposto por Hopper (1991), as formas que mudam de categoria linguística, passando de itens lexicais a itens gramaticais ou ainda de itens gramaticais a itens mais gramaticais não necessariamente se excluem no sistema linguístico, ou seja, um item pode assumir novas funções sem deixar de ser utilizado em sua forma de origem, como ocorre com o verbo DAR nos contextos por nós analisados. Ademais, segundo prevê o princípio da divergência de Hopper, o fato de uma forma ter passado de uma categoria lexical para uma categoria gramatical não impede que ela esteja sujeita a outros processos de mudança categorial, quer enquanto forma lexical quer enquanto forma gramatical. No caso do nosso estudo, o verbo DAR, após mudar da categoria de predicador para marcador de modalidade epistêmica, continuou seu percurso de mudança linguística, tornando-se um marcador aspectual, conforme ilustraram os exemplos (2) e (3).

Constitui, pois, nosso desafio ao longo deste texto traçar o continuum de gramaticalização do verbo DAR, buscando identificar os processos cognitivos atuantes no decurso da mudança categorial da forma, bem como descrever os fatores internos que a motivam. Para tanto, iniciaremos com a descrição da metodologia por nós adotada, apresentando, na seção seguinte, nossos resultados. 
Esclarecemos que, dadas as limitações de extensão deste texto, optamos por evocar, no momento da discussão dos dados, os teóricos que nos serviram de sustentação, abstendo-nos, portanto, de fazer um estado da arte do fenômeno.

\section{Descrição da metodologia adotada}

A opção por um estudo de natureza diacrônica se justifica pela tentativa de flagrar o percurso de mudança categorial do verbo DAR, buscando identificar em que século ele teria se iniciado na língua, bem como recompor seu continuum de mudança. Elegemos como banco de dados para composição de nosso corpus o sítio "Corpus do Português", organizado por Davies e Ferreira e disponível online. ${ }^{1}$ Esse corpus digital, composto de quarenta e cinco milhões de palavras, permite ao pesquisador controlar, inicialmente, três variáveis: (i) gênero textual: compõe-se de textos orais, de textos ficcionais, de textos jornalísticos e de textos acadêmicos; (ii) modalidade de português: congrega português europeu e português brasileiro; e (iii) tempo: reúne textos escritos do século XIV ao século XX.

Como nosso objetivo era flagrar o maior número possível de ocorrências no banco de dados, utilizamos, inicialmente, a ferramenta de busca disponível no próprio sistema, a saber: [dar]. Por meio desse código, selecionaram-se todas as ocorrências do verbo DAR, em todas as suas flexões. Adotamos, em seguida, procedimento semelhante para localizar as construções gramaticais: [dar] pra/ para [vr*]. Das variáveis possíveis de controle no corpus, selecionamos apenas o tempo, delimitando nosso estudo aos séculos XVIII, XIX e XX, já que as primeiras ocorrências da construção gramatical foram identificadas no século XVIII. Considerando-se a grande produtividade dessa forma verbal na língua portuguesa, sentimos necessidade de fazer um recorte em nosso corpus, o que deveria ser, a nosso ver, aleatório, para não favorecer ocorrências da forma em estudo, enviesando, assim, os resultados. Desse modo, extraímos as ocorrências de apenas dez laudas de cada um dos três séculos. Tais laudas foram selecionadas mediante um critério regular, a saber: a cada duas páginas coletadas, saltávamos cinco, sendo as seguintes as páginas selecionadas em cada século: 1, 2, 8, 9, 15, $16,22,23,29$ e 30 . Transpondo essas páginas para dados quantitativos, foram

1 Endereço para acesso ao banco de dados: <http://www.corpusdoportugues.org $>$. 
coletados 1000 dados em cada um dos séculos, dos quais restaram 2.773, após eliminarem-se as ocorrências repetidas.

Constituído o corpus da pesquisa, passamos à computação dos dados, separando as ocorrências em duas categorias mais abrangentes: (i) forma lexical e (ii) forma gramatical. Estas, por sua vez, foram subcategorizadas do seguinte modo: integraram a categoria lexical as ocorrências de predicador, de verbo leve, ${ }^{2}$ de expressão idiomática e de mesoconstrução, ${ }^{3}$ enquanto a categoria gramatical congregou os auxiliares modal e aspectual. Submetemos essas formas a um tratamento estatístico, para verificar sua frequência, critério importante para testarmos a hipótese da gramaticalização de predicador a auxiliar.

A partir do momento em que selecionamos as ocorrências de trinta laudas totais para integrar o corpus, e verificado que, nele, a forma gramatical só foi registrada no século XIX, dada sua baixa frequência no séc. XVIII, ${ }^{4}$ o número de ocorrências gramaticais flagradas foi bastante reduzido (oitenta e oito no total, conforme Tabela 1, apresentada na seção seguinte), o que nos impedia de traçar o continuum de gramaticalização do verbo selecionado para o estudo. Assim, optamos por retornar ao sítio do "Corpus do Português" e montar um corpus auxiliar constituído por todas as formas gramaticais identificadas no intervalo de tempo determinado para o estudo, para, a partir do critério da frequência, tentar reconstituir o percurso da mudança de [-gramatical] para [+gramatical], bem como analisar seus aspectos internos, como era nosso objetivo inicial. Com esse redimensionamento de procedimentos, ampliamos para 600 o número de

2 Nossa opção por considerar os verbos leves como formas lexicais se sustenta em dois argumentos defendidos por Gonçalves et al. (2010): (i) preservam parte do significado e a estrutura argumental da forma plena; (ii) são responsáveis pela seleção semântica do argumento externo.

3 Categorizaram-se como mesoconstruções estruturas formadas de $\mathrm{V} 1_{\text {Dar }}+\mathrm{PREP}+\mathrm{v} 2_{\text {infinitivo }}$ que, embora estruturalmente se assemelhem às construções gramaticais por nós analisadas, não apresentam, como estas, a propriedade de denotar modalidade ou aspecto. Assim, entendemos que estão num estágio intermediário, já que, estruturalmente, aproximam-se das construções e, funcionalmente, dos verbos leves, por poderem ser, assim como estes, parafraseadas por uma forma verbal simples, conforme se observa neste exemplo: "Não quero de forma nenhuma dar a entender que a privatização (...)" (séc. XX, grifos nossos). A expressão "dar a entender" pode ser parafraseada por "sugerir".

4 A partir da ferramenta de busca utilizada para identificar as ocorrências gramaticais no Corpus do Português, identificaram-se apenas oito estruturas constituídas de $\mathrm{V} 1_{\mathrm{DAR}}+\mathrm{PREP}+\mathrm{v} 2_{\text {infinitivo }}$ no século XVIII e nenhuma delas foi selecionada pelo recorte aleatório para composição de nosso corpus. Esclarecemos, contudo, que apenas uma dessas estruturas exibia contornos funcionais de marcação aspectual ("Vossa Mercê sabe que, quando me dá para falar, falarei por toda uma eternidade (...)"; séc. XVIII, grifos nossos). As demais eram meras justaposições de duas orações, sendo a segunda delas uma oração final introduzida pela preposição para, conforme ilustra este exemplo: “(...) basta-me as Luzes que Deus me deu para ir vivendo com os meus sossios (...)” (séc. XVIII, grifos nossos). Acreditamos, no entanto, ser esse o contexto sintagmático que permitiu a reanálise estrutural de que se originou a construção gramatical. 
ocorrências da forma gramatical, o que contabilizou um total geral de 3.288 dados.

Além do critério da frequência, também lidamos com o critério semântico, pautado na concretude/abstração da forma. Tal critério se faz importante para testar a hipótese da gramaticalização, porque, conforme defende Heine (2003), a passagem do item de lexical a gramatical pressupõe quatro mecanismos inter-relacionados, entre os quais a dessemantização, entendida como perda de conteúdo nocional, e a extensão, mecanismo sintático que consiste no uso da forma em novos contextos. Considerando-se que, desde os estudos seminais sobre a gramaticalização, entende-se que as formas gramaticais derivam historicamente de lexemas concretos, analisamos também a concretude/abstração da forma, tomando como sentido concreto do verbo a transferência de posse concreta e, como abstratos, os demais usos. Esse critério também se mostra relevante para tentarmos entender os processos cognitivos subjacentes ao processo de mudança categorial por nós estudado, conforme se verá quando da discussão dos dados.

\section{Apresentação e análise dos dados}

Considerando-se que, metodologicamente, trabalhamos com um corpus restrito a um período que compreende três séculos, conforme descrito na seção precedente, e, na sequência, redimensionamos esse corpus com o acréscimo de ocorrências gramaticais, nossa análise será desdobrada em duas subseções. $\mathrm{Na}$ primeira delas, ater-nos-emos primordialmente ao critério da frequência, com o intuito de testar a hipótese da gramaticalização no corpus restrito aos séculos XVIII, XIX e XX e, na segunda, voltaremos nossa atenção para a análise do corpus ampliado de formas gramaticais, com o objetivo de traçar o continuum da mudança, bem como de analisar a influência de aspectos cognitivos e linguísticos subjacentes ao processo.

\section{Análise do processo de gramaticalização do verbo DAR: de item lexical a construção gramatical}

O processo de gramaticalização tem sido não só entendido, como também definido de diversas formas, em decorrência, principalmente, da concepção de 
gramática adotada. Tal como a concebemos, a gramaticalização é um processo de mudança linguística por meio do qual uma forma lexical perde propriedades de significação externa devido a alterações semânticas que sofre no curso da língua e, a partir de relações sintagmáticas que estabelece em determinados contextos, assume propriedades de significação interna, tornando-se, assim, forma gramatical. Esse processo pode ainda envolver itens de uma mesma categoria, quando uma forma já gramatical se desloca numa escala gradual, tornando-se mais gramatical.

Estamos assumindo, assim como Lehmann, que "a gramaticalização não atinge apenas uma palavra ou morfema (...) mas toda a construção formada pelas relações sintagmáticas dos elementos em questão". 5 (LEHMANN, 1995, p. 406). Assim, no contexto específico de $\mathrm{V}_{\mathrm{DAR}}+\mathrm{PREP}_{\mathrm{p(a)ra}}+\mathrm{v} 2_{\text {infinitivo, }}$ em virtude das relações sintagmáticas estabelecidas entre $\mathrm{V} 1+$ preposição $+\mathrm{V} 2$, o verbo DAR se gramaticaliza, tornando-se uma construção, por meio da qual o falante pode expressar tanto a modalidade ${ }^{6}$ de seu discurso, quanto marcar o aspecto ${ }^{7}$ verbal.

Estabelecido o conceito de gramaticalização que subsidiou nosso estudo, passemos à análise da frequência diacrônica das formas lexical e gramatical cujo cômputo é apresentado na Tabela 1, a seguir:

Tabela 1 - Análise da frequência diacrônica do verbo DAR

\begin{tabular}{cccc}
\hline CATEGORIA & SÉC. XVIII & SÉC. XIX & SÉC. XX \\
\hline $\begin{array}{ccc}\text { Predicador } \\
\text { Verbo leve }\end{array}$ & $628(70,1 \%)$ & $654(71,7 \%)$ & $472(48,8 \%)$ \\
$\begin{array}{c}\text { Expressão } \\
\text { idiomática } \\
\text { Mesoconstrução }\end{array}$ & $69(7,7 \%)$ & $200(21,9 \%)$ & $232(24,0 \%)$ \\
Auxiliar modal & $07(0,9 \%)$ & $52(5,8 \%)$ & $174(18,0 \%)$ \\
Auxiliar aspectual & $0(0 \%)$ & $3(0,3 \%)$ & $3(0,3 \%)$ \\
\hline TOTAL & $0(0 \%)$ & $1(0,1 \%)$ & $84(8,8 \%)$ \\
\hline
\end{tabular}

Fonte: Dados coletados.

5 Grammaticalization does not merely seize a word or morpheme [...] but the whole construction formed by the syntagmatic relations of the elements in question."

6 Segundo Campos (2004), a modalidade explicita as diferentes atitudes do locutor em relação a um conteúdo proposicional e em relação ao seu interlocutor.

7 Travaglia define aspecto como "uma categoria verbal de TEMPO, não dêitica, através da qual se marca a duração da situação e/ou suas fases, sendo que estas podem ser consideradas sob diferentes pontos de vista, a saber: o do desenvolvimento, o do completamento e o da realização da situação". (TRAVAGLIA, 1985, p. 53). 
Os dados dispostos na tabela acima corroboram parcialmente a hipótese da gramaticalização. Isso porque, embora se verifique, ao longo dos três séculos, uma redução nos percentuais de frequência da categoria de predicador e uma discreta ampliação na categoria funcional dos auxiliares, o aumento da frequência total da forma ao longo dos séculos não decorre apenas do aumento da frequência gramatical, como prevêem os princípios da gramaticalização. Note-se que a expansão se dá também no âmbito do léxico, que compreende ainda as categorias verbo leve, ${ }^{8}$ expressão idiomática ${ }^{9}$ e mesoconstrução. Esse dado, contudo, não invalida a hipótese inicial, já que há, incontestavelmente, um processo de mudança em curso, pois, conforme demonstra o gráfico 1, no intervalo de três séculos, verifica-se um decréscimo do uso da forma como predicador. A curva descendente dessa categoria se acentua na passagem do século XIX ao XX, exato período em que ocorre uma expansão semântica no plano do léxico e em que surgem ocorrências gramaticais, as quais também exibem, nesse período, uma pequena ascensão, liderada pela expansão da função modal. Esses dados parecem sinalizar ainda que o processo de mudança, além de lento e gradual, se implementa no séc. XX, já que, conforme prevê a curva da mudança, nos primeiros momentos do processo, os índices da forma inovadora são mais baixos, tendendo a uma elevação no estágio intermediário do processo.

\footnotetext{
8 Segundo Scher, essa terminologia foi introduzida na linguística por Jespersen (1954) para se referir a uma "tendência do inglês moderno de fazer uso de um verbo tematicamente vazio, marcado por pessoa e tempo, ao qual se associa um elemento nominal, responsável pela idéia 'realmente importante' da sentença, ou seja, pelo evento ou ação expressos por ela". (SCHER, 2003, p. 205). Resenhando o trabalho de Poustma (1926), a autora sistematiza três características de construções com verbos leves, entre os quais o verbo DAR em sentenças como João deu um grito.: "(i) o verbo principal é semanticamente vago; (ii) o complemento nominal tem como núcleo um nome de ação, em geral deverbal, que realmente predica sobre eventos; (iii) há, em geral, uma paráfrase entre a construção com verbo leve e o verbo simples que corresponde ao núcleo nominal”. (SCHER, 2003, p. 205).

9 A expressão idiomática se caracteriza pelo fato de o significado da construção não resultar da soma dos significados originais dos termos que a compõem, como se observa em "dar com os burros n'água", por exemplo. Scher (2003) adverte que, além desse aspecto semântico, as expressões idiomáticas e os verbos leves se diferenciam pela produtividade, pois estas são bem menos produtivas que aqueles, tese confirmada por nossos dados.
} 
Gráfico 1 - Tendência de usos do verbo DAR no curso do tempo

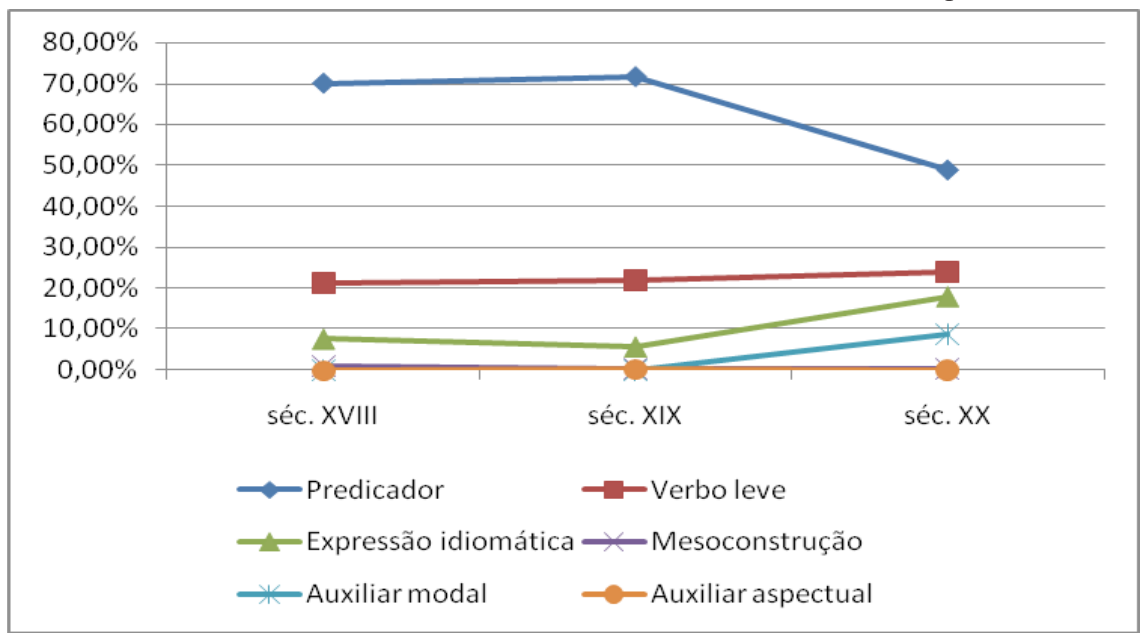

Fonte: Produção das autoras a partir dos dados coletados.

Outro aspecto relevante sinalizado pelos dados é a expansão relativamente paralela entre verbos leves, expressões idiomáticas e formas gramaticais, o que ocorre na contramão da curva do predicador. Isso confirma a tese de Coelho (2010) segundo a qual o processo de abstração semântica que desencadeia a gramaticalização pode igualmente incidir sobre o léxico, já que muitos usos, apesar de mais abstratos que a forma base, não alcançam o grau de abstração necessário para serem recrutados pela gramaticalização, cristalizando-se como novas formas lexicais. Além disso, a gramaticalização implica não só um processo cognitivo de natureza metafórica de abstração de semas, mas também processos metonímicos, estabelecidos pelas relações sintagmáticas entre os constituintes da construção. Dessa feita, ao se abstraírem, alguns itens apenas se expandem no léxico, criando outras possibilidades de uso, como as construções com verbos leves (cf. 4) e as expressões idiomáticas (cf. 5), enquanto outros mudam de categoria, passando de formas lexicais a gramaticais, segundo já ilustrado pelos exemplos de (1) a (3).

(4) "Se for outra a prioridade o governador também vai DAR seu apoio." (Séc. XX, grifos nossos.)

(5) "Mas, com frequência, DÁ o ar da graça em Bauru (...)” (Séc. XX, grifos nossos.) 
Por fim, no tocante ainda à frequência das formas gramaticais e à curva traçada no gráfico 1, notamos que, apesar de ambos surgirem no século XIX, os auxiliares modais e os aspectuais se difundem assimetricamente na língua. Isso pode indicar tanto uma tendência da amostragem quanto sinalizar que o estágio de gramaticalização do auxiliar aspectual é posterior ${ }^{10}$ ao do modalizador, o que será investigado no corpus ampliado de formas gramaticais.

\section{Análise do processo de gramaticalização do verbo DAR: de modal epistêmico a marcador aspectual}

Como já explicitado, uma vez gramaticalizada, uma forma pode continuar seu percurso de mudança, deslocando-se numa escala gradual de [-gramatical] para [+gramatical]. Nossos dados demonstram que o verbo DAR desempenha duas funções gramaticais distintas, quais sejam: (i) marcar a modalidade epistêmica e (ii) expressar mais de uma conotação aspectual. Resta-nos, portanto, tentar identificar qual é a forma mais gramatical, para, a partir de então, traçar o continuum de mudança.

Segundo Lehmann (1995), o grau de gramaticalização de um item é medido por sua autonomia, já que esta é postulada como incompatível com seu estatuto gramatical. Um dos recursos para medir semelhante autonomia é verificar a coesão sintagmática da construção, isto é, a integração das formas que se relacionam sintagmaticamente para constituir o todo semântico. Além da coesão, a variabilidade sintagmática também é um recurso para aferir a gramaticalidade, pois a posição fixa da forma dentro do sintagma é um indício de sua alta gramaticalidade. Valendo-nos apenas desses recursos, não nos é possível delimitar qual a forma [+gramatical], já que tanto na construção modal quanto na aspectual, nota-se uma forte coesão entre $\mathrm{V} 1_{\mathrm{DAR}}$ e os demais elementos da construção, não ocorrendo, nos dados, nenhum material interveniente entre eles. Também no tocante à fixidez da forma, ambas mostram-se fixas, já que ocupam a primeira posição da construção, ligando-se ao predicador ( $\mathrm{v} 2_{\text {infinitivo }}$ ) por meio da preposição. Resta-nos, pois, tentar recuperar o

10 A palavra "posterior" aqui empregada não visa a sugerir a precedência diacrônica dos modais, já que, conforme relatamos, identificamos uma ocorrência com contornos aspectuais no séc. XVIII e nenhuma com contornos modais. Trata-se de uma posterioridade no continuum dos níveis de gramaticalização. 
continuum da mudança, a partir da análise do critério da frequência das formas gramaticais, no corpus expandido. Considerando-se, conforme demonstrado na Tabela 1, que as primeiras ocorrências gramaticais são registradas, em nossa amostra, no século XIX e que seus índices são bastante próximos no período, não podemos precisar, com base apenas nesse dado, qual é mais antiga na língua. Assim, a partir das ocorrências identificadas no século XX e dispostas na Tabela 2, buscaremos subsídios que nos permitam recuperar o percurso de gramaticalização da forma verbal estudada, conjugando o critério da frequência com os parâmetros de gramaticalização postulados por Lehmann (1995) e por Hopper (1991) para aferir o grau de gramaticalização de uma forma.

Tabela 2 - Frequência da construção $V 1_{\text {DAR }}+p(a) r a+v 2_{\text {infinitivo }}$ no séc. XX

CONSTRUÇÃO

\section{OCORRÊNCIA}

MODAL

DAR PARA

DAR PRA

TOTAL
109

417

$526(87,67)$
ASPECTUAL 5

69

$74(12,33 \%)$

Fonte: Dados coletados.

Confirmando a tendência apresentada no gráfico 1, nota-se uma expansão das formas gramaticais fomentada pela categoria modal cuja frequência é consideravelmente maior que a dos auxiliares aspectuais. Tais dados podem sinalizar, se não que a forma modal precede a forma aspectual no percurso de mudança, pelo menos que seu processo de espraiamento está mais acelerado. Acredita-se, contudo, que os modais precedam historicamente os aspectuais e que são, portanto, menos gramaticais, já que estes são categorias da gramática, enquanto aqueles são categorias do discurso. Assim, na conhecida escala proposta por Givon (1971) para representar os estágios de desenvolvimento de uma forma gramatical, ${ }^{11}$ o DAR modal ocuparia o primeiro estágio, enquanto o DAR aspectual se alocaria no segundo. Essa hipótese faz eco com as palavras de Gonçalves e Carvalho (2007, p. 74), para quem “o número de verbos integrantes

11 "Discourse $>$ Syntax $>$ Morphology $>$ Morphophonemics $>$ Zero." (GIVON, 1971, p. 12). 
do paradigma dos auxiliares aspectuais é restrito, e (...), consequentemente, mais gramaticalizados". Além disso, considerando-se o parâmetro da variabilidade paradigmática proposto por Lehmann (1995), como mais um aferidor do grau de gramaticalização, nota-se que a variabilidade paradigmática dos modais é maior que a dos aspectuais, já que, na categoria de modalizador, a forma DAR pode ser substituída por outros auxiliares epistêmicos sem prejuízo semântico, enquanto o paradigma aspectual é mais restritivo, justamente pela função cumulativa assumida pela forma, conforme (6) a seguir:

(6) “(...) DEU pra falar com o demo. Leva a noite resmungando.” (Séc. XIX, grifos nossos.)

Nota-se, no excerto acima, que o aspecto inceptivo, isto é, aquele que assinala o início de uma ação - no caso, a ação de "falar" - poderia ser expresso pelo verbo “começar", por exemplo, cujo lexema já carrega a incoação. Contudo, a marcação do valor intensivo dessa ação, que termina por levar ao aspecto iterativo, não pode ser igualmente traduzida pela forma "começar", o que restringe a variabilidade paradigmática de V1, uma vez que essa posição só pode ser ocupada por formas verbais que, assim como "dar", são capazes de traduzir simultaneamente as conotações aspectuais analisadas. Tal restrição é mais um indício em favor do maior grau de gramaticalização da forma aspectual, que, desse modo, atualiza o parâmetro da especialização, proposto por Hopper (1991). A função de marcador aspectual assumida por V1 nessa construção faz com que ele seja interpretado como uma forma portmanteau, aproximando-se, em termos funcionais, da categoria dos morfemas cumulativos. Assim, pode-se considerar que a forma aspectual é seguramente mais gramatical que a forma modal, o que nos habilita a traçar o continuum de gramaticalização do verbo DAR, conforme nos propusemos a fazer: predicador $>$ auxiliar modal $>$ auxiliar aspectual.

Isso posto, cabe-nos descrever que fatores internos determinam a realização de funções gramaticais distintas, quando, superficialmente, a estrutura se realiza de modo semelhante. Nossa hipótese é a de que a fonte das formas gramaticais não é a mesma, isto é, os auxiliares modais originam-se de DAR pleno (predicador) e as formas aspectuais, de DAR leve. Nossa hipótese encontra respaldo em Gonçalves et al, que afirmam que, "no que toca à selecção do tipo de eventualidades, os verbos leves são sensíveis à classe aspectual do nome deverbal com o qual se combinam". (GONÇALVES et al. 2010, p. 458). Acreditamos, portanto, que o gatilho para a função aspectual desempenhada pelo DAR é, conforme cogita Coelho (2013), a persistência de um traço gramatical 
ligado, no caso, à seleção argumental do verbo leve e às propriedades aspectuais do complemento desse verbo. Gonçalves et al. (2010), ao compararem as propriedades aspectuais dos verbos leves dar, fazer e ter constataram que o verbo objeto de nosso estudo é o mais restritivo dos três no que toca às classes aspectuais com as quais formam as nominalizações.

Visando a uma caracterização dos verbos leves em termos de um conjunto de traços de propriedades aspectuais, os linguistas da Universidade de Lisboa chegaram à seguinte grade: "dar ${ }_{\text {leve }}:[+$ dinâmico], $[ \pm$ mudança], $[ \pm$ causa $],[ \pm$ durativo $],[ \pm$ instant]" (GONÇALVES et al., 2010, p. 459). Essa grade determina, segundo defendem os referidos autores, a seleção aspectual do nome deverbal que irá integrar a construção $\mathrm{V}_{\text {DAR leve }}+\mathrm{N}$. Estendendo essa restrição para a construção sintagmática das perífrases aspectuais, já que estamos assumindo que estas são originárias do verbo leve, nossa expectativa é de que as propriedades dos demais elementos integrantes da construção verbal, isto é, da preposição e de V2, também sejam compatíveis com os traços de V1. Acreditamos que a chave para entender a multifuncionalidade que as construções encabeçadas por $V 1_{D A R}$ assumem na língua resida na interação sintagmática entre alguns traços apresentados na grade acima, conforme passamos a demonstrar.

$\mathrm{O}$ primeiro traço atribuído ao verbo leve diz respeito à dinamicidade, o que o torna incompatível com estados, segundo constataram os autores ora referenciados. Nessa perspectiva, era de esperar que as construções com V2 de estado fossem agramaticais na língua, mas, embora menos produtivas, foram identificadas em nosso corpus, conforme ilustra (7):

(7) “(...) se casou rico e DEU para ser católico praticante.” (Séc. XX, grifos nossos.)

Travaglia (1985), ao descrever as perífrases inceptivas, não inclui aquelas constituídas com o verbo DAR no contexto acima ilustrado, por entender que elas não são propriamente inceptivas. Segundo ele, tais construções traduzem antes a aptidão ou a predisposição para algo. ${ }^{12}$ Considerando-se que, conforme defende Lehmann (1995), a gramaticalização atinge toda a construção, é preciso analisar também os traços dos demais elementos que a constituem, bem como as relações que se estabelecem sintagmaticamente, para tentar entender sua gramaticalidade. $O$ verbo DAR pleno denota movimento, já que expressa mudança de localização de uma

12 Em construções como "Ele não dá para (ser) professor, pois tem dificuldade de se expressar em público", em que Travaglia (1985) reconhece a propensão para o exercício de uma profissão, parece-nos haver, conforme Heine (1993), uma ambiguidade entre as duas formas: A (modal) e B (aspectual). Isso suscita a hipótese de que seja esse o contexto semântico favorecedor da reanálise modal $>$ aspectual. 
entidade, propriedade preservada no verbo leve pelo traço [ \pm mudança]. Essa noção de movimento é reforçada, na construção aspectual, pela preposição, que indica direção, traduzindo a propensão do indivíduo para determinado estado ou mesmo tarefa. Essa extensão de uso decorre, segundo nossa interpretação, de um processo metafórico que atua sobre o verbo leve em seu processo de gramaticalização e constitui o gatilho para a tradução do aspecto inceptivo em construções como a ilustrada em (7), já que a propensão para a prática do catolicismo assinala uma mudança de estado e, portanto, o início de uma prática antes não adotada.

Lakoff e Johnson (1980) desenvolvem a teoria da metáfora conceptual, propondo uma relação de interdependência entre esta e a experiência humana no mundo. Nessa perspectiva, as metáforas do caminho são processadas com base na simulação do movimento de um corpo que se desloca de um ponto A para um ponto B, pois a experiência do movimento físico do deslocamento facilita, segundo os autores, o processamento de um conceito de um domínio cognitivo concreto para um abstrato. Apoiada na tese desses autores, Sigiliano (2012) defende que a motivação cognitiva para empregar verbos auxiliares (V1) não prototípicos em construções inceptivas é a metáfora do movimento, o que, no caso do nosso estudo, é reforçado pela preposição "p(a)ra", que é o segundo elemento da construção. Assim, essa extensão de usos licencia construções com V2 de estado, já que seu caráter [-dinâmico] é neutralizado tanto pela abstração metafórica do movimento, quanto pela coesão com os outros elementos do composto.

Nas construções aspectuais por nós analisadas, os traços [ \pm causa] e [ \pm durativo] também impõem restrições à combinação sintagmática, ao mesmo tempo em que contribuem para atualizar o valor intensivo e, consequentemente, iterativo da construção. Dado que, conforme atestado por Gonçalves et al. (op. cit.), a despeito de seu traço [ \pm durativo], $\mathrm{DAR}_{\text {leve }}$ só atualiza processos culminados, excluindo as culminações, os verbos que ocupam a posição de V2 são preferencialmente verbos de evento e de processo, que se prestam com maestria a traduzir o valor intensivo da construção. Em virtude da atualização dos processos culminados de V1, esperava-se que V2 fosse de natureza télica. ${ }^{13}$ Contudo, há de se considerar, primeiramente, que os verbos télicos são pontuais e, portanto, incompatíveis com a duração, que traduz o valor intensivo responsável pela iteração ou pluralidade do evento ou processo expresso por V2. Agregue-se a isso a coesão sintagmática da construção cujo segundo

13 Denominam-se télicos aqueles verbos que indicam uma situação que chegou, obrigatoriamente, a um fim, por oposição aos atélicos, que se referem a uma situação que não tende necessariamente a um fim. 
elemento é uma preposição atélica, o que acaba por favorecer a ocorrência de verbos atélicos na posição de V2. Dessa forma, as construções com V2 télico são pouco produtivas no corpus e, conforme ilustram (8) e (9), a seguir, têm sua gramaticalidade subordinada a contextos muito especiais, em que a iteração se subordina à existência de sujeitos distintos, já que os verbos "morrer" e "nascer" não são passíveis de se repetirem para um mesmo sujeito.

(8) “(...) teve uma época que os colegas dele DERAM para morrer, quando eu perguntava, de que morreu esse seu amigo? ele dizia que foi de repente." (Séc. XX, grifos nossos.)

(9) "Lá num canto, Dentinho de Arroz descobriu caruru. DEU para nascer também beldroega.” (Séc. XX, grifos nossos.)

Acreditamos que o licenciamento de construções com verbos télicos na posição de V2 decorra de uma neutralização de traços determinada pela coesão sintagmática. A despeito da incompatibilidade da telicidade com o traço [ \pm durativo], conforme já comentado, no tocante ao traço [ ${ }_{\text {instant }}$, segundo constatação de Gonçalves et al. (op. cit.), o verbo $\mathrm{DAR}_{\text {leve }}$ seleciona preferencialmente eventos sem estrutura fásica, propriedade que é prontamente satisfeita pelos verbos télicos identificados por nós.

Tendo analisado os fatores subjacentes ao processo de gramaticalização do verbo DAR de predicador a auxiliar e descrito diacronicamente seu processo de abstração, que incidiu tanto no léxico quanto na gramática, cremos ser possível, a partir dos dados levantados e das reflexões empreendidas, delinear seu continuum de mudança categorial, o qual representamos por meio do seguinte diagrama:

LEXICAL

$>$

GRAMATICAL

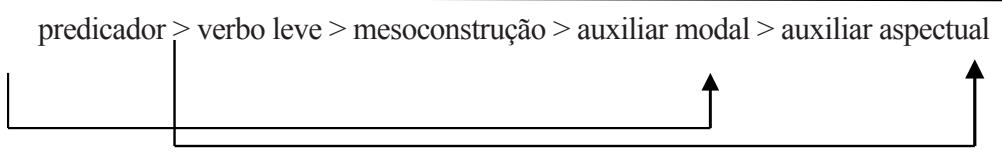

\section{Considerações finais}

Visando a testar a hipótese da mudança categorial do verbo DAR de predicador a auxiliar, empreendemos um estudo de natureza diacrônica, tomando como 
corpus um conjunto total de 3.288 dados coletados no sítio Corpus do Português. Além de tentar traçar o percurso da mudança, buscamos analisar alguns fatores semânticos e cognitivos subjacentes a esse processo.

As reflexões empreendidas levam-nos a crer que o processo de gramaticalização do verbo DAR tenha se implementado na língua no século XX, período em que há uma redução dos usos como predicador e uma ligeira expansão dos usos como auxiliar, liderados pela função modal. O processo semântico de abstração por que passou o verbo ao longo de seu percurso de mudança refletiu tanto no léxico quanto na gramática. No plano do léxico, provocou o surgimento de verbos leves, de expressões idiomáticas e de mesoconstruções, estágios intermediários entre a forma lexical e a gramatical. No plano da gramática, as duas construções auxiliares, apesar de estruturalmente semelhantes, assumem funções diferentes em virtude das formas que lhes serviram de fonte. Assim, defendemos que os auxiliares aspectuais constituem estágios mais gramaticais que os modais e se originaram dos verbos leves, enquanto os modais epistêmicos são oriundos dos predicadores. Estamos conscientes de que as intuições aqui apresentadas são ainda bastante embrionárias, mas esperamos que funcionem como uma alavanca para estudos futuros.

\title{
The continuum of grammaticalization of the verb TO GIVE: from predicator to auxiliary
}

\begin{abstract}
This research has investigated, in a diachronic perspective, the process of grammaticalization of the verb TO GIVE in Portuguese, in order to trace its continuum of grammaticalization. Taking as an object of analysis a corpus constituted of 3.288 occurrences of the word selected by the study, collected in the database of the Portuguese Corpus (DAVIES; FERREIRA, 2006), it was found that, over the centuries, this verb changed its category from predicator to auxiliary. This multifunctionality is a result of a cognitive process of semantic abstraction, which in the course of its linguistic history made the verb lose some of its grammatical properties - including the ability to select arguments - instead of incorporating other - as the expression of the modality and the verbal aspect - in constructions whose structure is as follows: $\mathrm{V} 1_{\mathrm{GIVE}}+\operatorname{PREP} p(a) r a+\mathrm{V} 2_{\text {Infinitive }}$. The analysis allowed us to get to the following continuum of change: predicator $>$ light verb $>$ mesoconstruction $>$ modal epistemic $>$ aspect marker.
\end{abstract}

Keywords: Grammaticalization. Verbal periphrasis. Iterative aspect. Inchoative aspect. Modality. 
Referências

CAMPOS, Maria Henriqueta Costa. A modalidade apreciativa: uma questão teórica. In: OLIVEIRA, Fátima; DUARTE, Isabel Margarida (Org.). Da língua e do discurso. Porto: Campo das Letras, 2004. p. 265-281.

CASTILHO, Ataliba Teixeira de. Introdução ao estudo do aspecto verbal na língua portuguesa. Marília: FFCL de Marília, 1968.

COELHO, Sueli Maria. Expansão gramatical e expansão lexical: dois processos linguísticos paralelos. In: VITRAL, Lorenzo Teixeira; COELHO, Sueli Maria (Org.). Estudos de gramaticalização em português: metodologias e aplicações. Campinas, SP: Mercado de Letras, 2010. cap. 12, p. 333-346.

COELHO, Sueli Maria. Gradualismo do processo de gramaticalização e princípio da persistência: indícios de uma hierarquia de traços? Filologia e Linguística Portuguesa, São Paulo, v. 15, n. 2, p. 519-541, jan./jun. 2013. No prelo.

DAVIES, Mark; FERREIRA, Michael J. Corpus do Português: 45 million words, 1300s-1900s. Disponível em: <http://www.corpusdoportugues.org>. Acesso em: 2006.

GIVON, Talmy. Historical syntax and synchronic morphology: an archaeologist's field trip. Papers from the 7th Regional Meeting. Chicago: Chicago Linguistic Society, 1971.

GONÇALVES, Sebastião Carlos Leite; CARVALHO, Cristina dos Santos. Critérios de gramaticalização. In: GONÇALVES, Sebastião Carlos Leite; LIMA-HERNANDES, Maria Célia; CASSEB-GALVÃO, Vânia Cristina (Org.).

Introdução à gramaticalização: princípios teóricos e aplicação. São Paulo: Parábola Editorial, 2007. cap. 2, p. 67-90.

GONÇALVES, Anabela et al. Propriedades predicativas dos verbos leves dar, ter e fazer: estrutura argumental e eventiva. In: ENCONTRO NACIONAL DA ASSOCIAÇÃO PORTUGUESA DE LINGUÍSTICA, 25., 2009, Lisboa. Textos selecionados. Porto, APL, 2010. p. 449-464.

HEINE, Bernd. Auxiliaries: cognitive forces and grammaticalization. New York: Oxford University Press, 1993.

HEINE, Bernd. Grammaticalization. In: JOSEPH, Brian D.; JANDA, Richard D. (Org.). The handbook of historical linguistic. Oxford: Blackwell, 2003. 
HOPPER, Paul J. On some principles of grammaticalization. In: TRAUGOTT, Elizabeth Closs; HEINE, Bernd (Org.). Approaches of grammaticalization. Amsterdam: John Benjamins, 1991. p. 17-36.

HOPPER, Paul J.; TRAUGOTT, Elizabeth C. Grammaticalization. $2^{\text {nd }}$ ed. Cambridge: Cambridge University Press, 2003.

LABOV, William. Sociolinguistics patterns. Philadelphia: University of Pennsylvania, 1972.

LAKOFF, George; JOHNSON, Mark. Metaphors we live by. Chicago: The Chicago University Press, 1980.

LEHMANN, Christian. Thoughts on grammaticalization. Munich: Lincom Europa (originalmente publicado como Thoughts on grammaticalization: a programmatic sketch. Köln: Arbeiten des Kölner Universalienprojekts 49 - v. 1.), 1995. Original publicado em 1982.

SCHER, Ana Paula. Quais são as propriedades lexicais de uma construção com verbo leve? In: MÜLLER, Ana Lúcia; NEGRÃO, Esmeralda Vailatti; FOLTRAN, Maria José (Org.). Semântica formal. São Paulo: Contexto, 2003. p. 205-219.

SIGILIANO, Natalia Sathler. Evidências translinguísticas da metáfora de movimento na construção de aspecto incentivo. Revista Linguística, Rio de Janeiro, v. 8, n. 1, p. 32-48, jun. 2012.

TRAVAGLIA, Luiz Carlos. O aspecto verbal no português: a categoria e sua expressão. Uberlândia: Imprensa Universitária, 1985. Original publicado em 1981. VELLOSO, Mônica Monken. Um estudo da idiomatização da construção modal com o verbo DAR no português do Brasil. Dissertação (Mestrado em Linguística) - Faculdade de Letras, Universidade Federal de Juiz de Fora, Juiz de Fora, 2007. 